\title{
Larva migrans cutânea - um caso de apresentação típica no viajante
}

Conceição Alves, * Vanda Proença**

\section{RESUMO}

A larva migrans cutânea é a dermatopatia mais comum em turistas regressados das regiões tropicais, sendo que na maioria dos países industrializados os casos são importados.

Apresenta-se o caso clínico de uma mulher de 31 anos que recorreu à médica de família por lesão eritematosa, serpiginosa e pruriginosa no dorso do pé, com três meses de evolução, que terá surgido após viagem à Jamaica. Pela clínica e contexto epidemiológico diagnosticou-se infecção por larva migrans cutânea. A utente foi medicada com albendazol, com resolução completa da lesão.

Apesar desta patologia ser pouco frequente nos nossos cuidados de saúde primários, é importante estar incluída nas hipóteses diagnósticas de lesões cutâneas nos turistas, dado o recurso crescente a viagens internacionais.

Palavras-chave: Larva migrans; Dermatologia; Medicina de Viagem.

\section{INTRODUÇÃO}

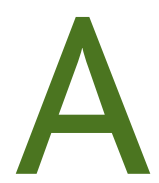

patologia dermatológica é a terceira causa mais comum de morbilidade nos turistas (a seguir à diarreia e aos sintomas respiratórios), com uma incidência estimada de até 8\%. ${ }^{1}$ A larva migrans cutânea é a dermatopatia mais comum em turistas originários de regiões tropicais. ${ }^{1}$

Embora pouco frequente nos cuidados de saúde primários de países com climas temperados como Portugal, poderá ocasionalmente aparecer no consultório dada a facilidade e procura crescente de viagens internacionais.

Segue-se a descrição do caso clínico de uma utente regressada da Jamaica com uma história clínica e alterações cutâneas típicas, que permitiram o diagnóstico e tratamento dirigidos, com resolução eficaz do quadro.

\section{DESCRIÇÃO DO CASO}

Uma mulher de 31 anos recorreu à consulta da médica de família em Abril de 2011, referindo o aparecimento de lesão eritematosa e pruriginosa no quinto dedo do pé esquerdo três meses antes, coincidente com

*Interna de Medicina Geral e Familiar, USF S. Julião, ACES de Oeiras.

**Assistente de Medicina Geral e Familiar, USF S. Julião, ACES de Oeiras. viagem que fez à Jamaica. Por suspeita de tinea pedis, aplicou por sua iniciativa antifúngicos tópicos, mas sem melhoria. Pelo contrário, houve uma alteração da lesão inicial, com formação de cordão eritematoso e pruriginoso no dorso do pé.

Ao exame objectivo, observou-se uma lesão eritematosa de formato linear com trajecto tortuoso na face dorsal externa do pé esquerdo (figura 1).

Com base na clínica e no contexto epidemiológico, fez-se o diagnóstico de larva migrans cutânea, medicando-se com albendazol $400 \mathrm{mg}$ em toma única, durante três dias, com regressão completa da lesão.

\section{COMENTÁRIO}

A larva migrans cutânea é causada por nemátodos do género Ancylostoma, mais frequentemente o Ancylostoma braziliense e o Ancylostoma caninum. ${ }^{1,2}$ As regiões endémicas englobam as zonas balneares tropicais e subtropicais do sudeste asiático, África, América do Sul, sul dos Estados Unidos e Caraíbas. ${ }^{1}$

Os humanos são hospedeiros acidentais e de final de vida destes parasitas, adquiridos através do contacto com ambiente contaminado por fezes de cães ou gatos infestados. $^{2} \mathrm{~A}$ infecção pode ser contraída nas regiões 
endémicas sempre que as condições de calor e humidade do solo forem propícias ao desenvolvimento da larva. Esta penetra através da pele intacta pelos folículos pilosos e glândulas sudoríparas ou através de fissuras cutâneas, ficando habitualmente confinada à epiderme e derme superficial. ${ }^{1,3} \mathrm{~A}$ incubação é curta: horas a dias e raramente mais do que um mês. O prurido inicia-se horas após a penetração da larva. Desenvolve-se uma erupção eritematosa, serpiginosa ou linear, pruriginosa, correspondente ao trajecto de migração da larva. ${ }^{1}$ As lesões distribuem-se por locais expostos da pele, mais comummente os pés, pernas, nádegas e mãos. $^{2}$

Na maioria dos casos há resolução espontânea das lesões em duas a oito semanas (raramente até dois anos). ${ }^{1,2}$ As complicações mais comuns incluem impétigo, foliculite, edema e reacções vesículo-bolhosas. ${ }^{3}$ Há, contudo, casos descritos de disseminação hematogénea, com envolvimento pulmonar e desencadeamento da síndrome de Loeffler (eosinofilia pulmonar). ${ }^{2-4}$

O diagnóstico é clínico, baseado na história que inclui referência a viagem para uma zona endémica e na observação de lesões cutâneas típicas. Não está recomendado biopsar a lesão, uma vez que a larva se encontra distanciada alguns centímetros do trajecto visível. ${ }^{1,3}$

Não obstante a possibilidade de resolução espontânea, o tratamento torna-se necessário de forma a diminuir a duração da doença, evitar o prurido intenso e obviar potenciais complicações. ${ }^{3} \mathrm{O}$ fármaco de escolha disponível em Portugal é o albendazol nas doses de 400 a $800 \mathrm{mg} /$ dia no adulto e de 10 a $15 \mathrm{mg} / \mathrm{Kg} /$ dia na criança, durante 3 a 5 dias consecutivos. O albendazol oral não está recomendado na grávida por risco de teratogenicidade, não havendo evidência da segurança de outros tratamentos farmacológicos. ${ }^{1-3}$

O médico de família deve alertar os utentes que viajam para praias e climas tropicais sobre o risco de infestação por esta larva e as respectivas medidas preventivas. Estas passam por evitar andar descalço ou ter a pele em contacto directo com solos quentes e húmidos dessas regiões ou de terrenos fertilizados com excrementos de animais. ${ }^{5}$

Em conclusão, a infecção por larva migrans cutânea é de fácil diagnóstico e tratamento. No entanto, não é ainda correctamente identificada em mais de metade

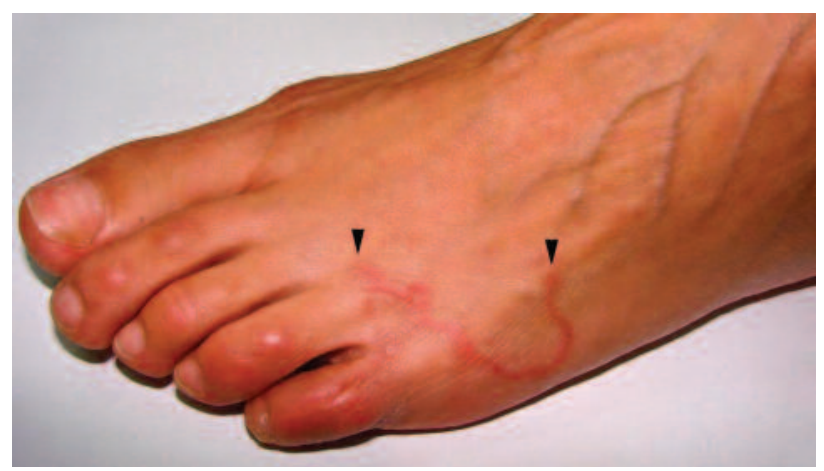

Figura 1. Lesão eritematosa serpiginosa causada por larva migrans cutânea, em mulher regressada da Jamaica.

dos casos, pelo que esta hipótese diagnóstica deve ser considerada aquando de lesões cutâneas que surjam de novo em turistas, sobretudo nos oriundos de regiões tropicais. ${ }^{1}$

\section{AGRADECIMENTOS}

As autoras estão gratas ao colega Dr. Daniel Pinto pelos comentários críticos e ajuda técnica que prestou no desenvolvimento deste trabalho.

\section{REFERÊNCIAS BIBLIOGRÁFICAS}

1. O'Brien BM. A practical approach to common skin problems in returning travellers. Travel Med Infect Dis 2009 May; 7 (3): 125-46.

2. Wolff $K$, Johnson RA, Suurmond R. Insect Bites and Infestations. In: Fitzpatrick's Color Atlas \& Synopsis of Clinical Dermatology. 5th ed. New York: McGraw-Hill; 2005. p.862-4.

3. Patel S, Sethi A. Imported tropical diseases. Dermatol Ther 2009 NovDec; 22 (6): 538-49.

4. Weller PF, Leder K. Cutaneous larva migrans (creeping eruption). UpToDate 2011.

5. Centre for Control and Disease. 2012 Yellow Book. Chapter 3 - Infectious Diseases Related To Travel. Cutaneous Larva Migrans. Disponível em: http://wwwnc.cdc.gov/travel/yellowbook/2012/chapter-3-infectious-diseases-related-to-travel/cutaneous-larva-migrans.htm [acedido em 08/02/2012].

\section{CONFLITO DE INTERESSES E FINANCIAMENTO}

As autoras declaram não possuir qualquer conflito de interesses e não existirem quaisquer fontes de financiamento para o artigo.

\section{ENDEREÇO PARA CORRESPONDÊNCIA}

Conceição Alves

Rua Central, n. ${ }^{\circ} 102$

4495-019 Aguçadoura (Póvoa de Varzim)

sao.alves@gmail.com

Recebido em 14/10/2011

Aceite para publicação em 12/02/2012 


\section{ABSTRACT}

\section{LARVA MIGRANS - A CUTANEOUS PRESENTATION IN A TOURIST}

Cutaneous larva migrans is the most common dermatosis diagnosed among tourists returning from tropical areas to temperate regions. In most developed countries, cases are imported.

We report the case of a 31-year-old woman who visited her family doctor because of an erythematous, serpiginous, pruritic lesion on the dorsum of her foot, that began three months previously, after returning from a visit to Jamaica. These clinical and epidemiologic features facilitated the diagnosis of cutaneous larva migrans infection. The patient was treated with albendazole, with complete recovery of the lesion.

Although rarely diagnosed in primary health care in Portugal, this disease should be included in the differential diagnosis of cutaneous lesions found in tourists, given the increase in travel to tropical regions.

Key-words: Larva migrans; Dermatology; Travel Medicine. 